\title{
Nutrition labelling: an exploratory study on personal factors that influence the practice of reading nutrition labels among adolescents
}

\author{
Norsakira Jefrydin ${ }^{1}$, Norazmir Md Nor $^{2,4} \&$ Ruzita Abd. Talib ${ }^{1,3^{*}}$ \\ ${ }^{1}$ Nutritional Sciences Programme, Faculty of Health Sciences, Universiti Kebangsaan \\ Malaysia, 50300 Kuala Lumpur, Malaysia; ${ }^{2}$ Centre of Nutrition and Dietetics, Faculty \\ of Health Sciences, Universiti Teknologi MARA, 42300 Puncak Alam, Selangor, \\ Malaysia; ${ }^{3}$ Center For Community Health, Faculty of Health Sciences, Universiti \\ Kebangsaan Malaysia, 50300 Kuala Lumpur, Malaysia; ${ }^{4}$ Food Service Quality \\ Research Group, Faculty of Hotel \& Tourism Management, Universiti Teknologi MARA, \\ 42300 Puncak Alam, Selangor, Malaysia
}

\begin{abstract}
Introduction: The consumption of processed food is increasing in developing countries. Nutrition labels on food packaging are important for the education of consumers, particularly adolescents, to help them make healthier food choices. However, there is evidence to suggest that adolescents generally do not use nutrition labels. This study aims to explore the personal factors that influence the practice of Malaysian adolescents in reading nutrition labels. Methods: The participants were adolescents, aged 13-16 years, from five public schools in Negeri Sembilan. Five semi-structured focus group discussions (FGDs) were conducted. The participants discussed their personal views, knowledge and perceptions regarding the use of nutrition labels and food selection. Data gathered from the FGDs were coded through thematic analysis using the NVivo software. Results: While the participants were familiar with nutrition labels, their usage was relatively low during food selection due to the lack of interest in nutrition information, past experiences, hunger and cravings, time constraints and the taste of the food. The main reasons for using nutrition labels were health consciousness and their curiosity about specific nutrition information provided on the labels. The majority of participants believed that information provided on the labels was accurate because it was provided by reliable institutions. There was also misperception among some participants, mixing up nutrition labels with list of ingredients and the expiry dates. A few participants were unconvinced by the labels and stated that the labels provided misleading information. Conclusion: Personal factors such as knowledge, misperception, awareness and trust significantly impact how adolescents read nutrition labels.
\end{abstract}

Keywords: Nutrition labels, adolescents, food choice, focus group discussion

\section{INTRODUCTION}

Several studies have demonstrated that processed food and beverages contribute to the increased intake of fat, sugar, and salt (Baker \& Friel, 2014). Ochola and Masibo (2014) showed that the widespread consumption of processed

\footnotetext{
*Corresponding author: Prof Ruzita Abd. Talib

Nutritional Sciences Programme, Faculty of Health Sciences, Universiti Kebangsaan Malaysia 50300 Kuala Lumpur, Malaysia

Tel: (6)0326947621; Fax: (6)(03)26947621; E-mail: rzt@ukm.edu.my

doi: https://doi.org/10.31246/mjn-2018-0123
} 
foods such as bread, biscuits, carbonated drinks, ice cream, canned sausage and cheese among adolescents contributes to the high prevalence of obesity. In order to prevent the excessive intake of processed foods and to make healthier food choices, i.e. to consume foods that are low in sugar, salt, and saturated fats, it is important that adolescents be motivated to read nutrition labels (Jun et al., 2011).

As nutrition labels provide important information regarding the nutrient content of a food, they can guide consumers in the selection of food. In Malaysia, nutrition labels must include a nutrition information panel (NIP) with information on energy, protein, carbohydrate and fat content. Nutrition labels must be displayed on packaged foods and beverages ( $\mathrm{MOH}$ Malaysia, 2010).

The National Health and Morbidity Survey (NHMS) 2014 (IPH, 2014) revealed that the percentage of Malaysians who do not read nutrition labels had increased to $55.0 \%$ from $19.3 \%$ in 2006 (IPH, 2006). Norazmir et al. (2012) reported that $53.6 \%$ of Malaysian youth did not use nutrition labels, while $69.5 \%$ did not understand it. Among Malaysian adolescents, 33.0\% have been reported as always reading nutrition labels when purchasing food and only $24.8 \%$ of Malaysian adolescents were interested in nutrition information (IPH, 2017). Other studies have noted that a low percentage of adolescents use nutrition labels and most of them did not understand the information (Talagala \& Arambepola, 2016; Wojcicki \& Heyman, 2012). Therefore, nutrition education is important to increase awareness and use of nutrition labels. However, most nutrition education in Malaysia focuses on nutrition per se (Talib et al., 2013), physical activity (Poh \& Nor Izzati, 2016) and behavioural modification (Yahya et al., 2017).
The present study aims to explore the personal factors that influence the use of nutrition labels amongst Malaysian adolescents.

\section{MATERIALS AND METHODS}

\section{Study design and location}

Data on the use of nutrition labels and the factors that influence this practice were gathered using focus group discussions (FGDs). The study was conducted in Negeri Sembilan, a state located in the central region of Peninsular Malaysia. Negeri Sembilan was selected because the prevalence of obesity among children and adolescents there $(12.5 \%)$ was higher than that for the same group nationally (11.9\%) (IPH, 2015).

\section{Ethical Approval}

The study procedures received approval from the National University of Malaysia (UKM) Ethics Board, the Malaysian Ministry of Education and the Negeri Sembilan State Department of Education.

\section{Participants}

The adolescents who participated in this study were recruited from five public secondary schools in both urban and rural areas. The schools were randomly selected from a list of public secondary schools located in four districts of Negeri Sembilan, namely, Seremban, Kuala Pilah, Port Dickson and Tampin. The students were eligible to participate in the study if they were adolescents aged 13-16 years, capable of reading and understanding the Malay language and had received the consent of their parents or guardians. Adolescents who were obese and diagnosed with common chronic diseases such as diabetes or asthma or who were on specific diet plans were excluded from the study. One hundred and fourteen participants were 
screened prior to the study. Thirty-four participants met the inclusion criteria for the study.

\section{Focus group discussion}

Participants were asked to complete a demographic questionnaire prior to the FGD session. Five FGDs were conducted in five different public schools. Each session was held in a private room and the session lasted 55 minutes. The sessions were conducted in the Malay language. Two researchers facilitated the focus groups. One researcher acted as a moderator and the other took detailed notes. The moderator used validated, semi-structured interview questions that allowed the participants to generate new ideas and explore specific topics. The participants were informed that the discussion would be audio-recorded and that would not be shared with any third party.

The discussions began with an introduction by the moderator and a warm-up session. The moderator then briefly explained the objectives of the focus group and emphasised that the discussion would be confidential. The main discussion included questions exploring the personal, behavioural and environmental factors that influence the practice of reading nutrition labels among adolescent participants. Followup questions were asked to obtain additional details about the discussion topic and to allow the participants to clarify what they had said. The discussion ended with a summary of the entire discussion by the moderator and final comments from the participants. Table 1 shows the questions asked in this study.

\section{Data collection and analysis}

Data on the demographic characteristics of the participants were analysed descriptively. Audio-recorded discussions and field notes were transcribed verbatim onto a Microsoft Word document. Data cleaning was performed to ensure that the responses were correct and matched with the corresponding participant. Once the transcripts were finalised, the qualitative software QSR NVivo version 11 was used to analyse the data. Data were systematically and automatically coded by using main themes based on social cognitive theory: personal, behavioural and environmental factors (Bandura, 1986). After the coding process was completed, sub-themes were identified through the frequency of coding within similar factors from all focus groups. To ensure the reliability of the data, three researchers undertook the coding process. They reached an inter-rater correspondence of $90 \%$. Finally, three experts evaluated the outcomes of the analysis to determine the value of Cohen's Kappa $(\mathrm{K})$ based on the agreement of the experts (Landis \& Koch, 1977). The calculated $\mathrm{K}$ value for this study was 0.84 , which indicates significant agreement.

\section{RESULTS}

\section{Participants}

Demographic characteristics of the participants are shown in Table 2. Of the 34 eligible participants, only 33 participated in the discussions. One of the participants was absent from school during the FGD session. Most of the participants were female, aged 14 years old and Malay. More than half $(55.0 \%)$ of the participants had bought pre-packaged food once or twice a week. The majority (90.9\%) reported that they are aware of nutrition labels on food packages. However, only $24.2 \%$ reported they always read nutrition labels when purchasing such food.

The outcomes of personal factors were organised into themes based on the responses from participants. These were knowledge, misperception, awareness 
Table 1. Interview guide of the focus group discussion

\begin{tabular}{|c|c|c|}
\hline \multirow{3}{*}{$\begin{array}{l}\text { Topic } \\
\text { Personal factor }\end{array}$} & \multicolumn{2}{|c|}{ Question } \\
\hline & 1. & Do you know what the nutrition label is? \\
\hline & & Probe: What do you understand about the nutrition label? \\
\hline & 2. & $\begin{array}{l}\text { What is your opinion on the importance of the nutrition label? } \\
\text { Probe: Do you trust the information on the nutrition label? }\end{array}$ \\
\hline \multirow[t]{5}{*}{$\begin{array}{l}\text { Behavioural } \\
\text { factor }\end{array}$} & 3. & $\begin{array}{l}\text { Do you read/use the nutrition label when purchasing packaged } \\
\text { food or beverages? }\end{array}$ \\
\hline & & $\begin{array}{l}\text { Probe: Can you explain why you read/do not read the nutrition } \\
\text { label when purchasing packaged food or beverages? }\end{array}$ \\
\hline & 4. & $\begin{array}{l}\text { Does the nutrition label influence you to buy packaged food or } \\
\text { beverages? }\end{array}$ \\
\hline & 5. & $\begin{array}{l}\text { Can you name three types of information that you searched for } \\
\text { when you read the nutrition label? } \\
\text { Probe: Can you explain why you chose the information? }\end{array}$ \\
\hline & 6. & $\begin{array}{l}\text { These are two same products. Please choose one of the products } \\
\text { based on their nutrition information. Then, please explain why you } \\
\text { chose this product. }\end{array}$ \\
\hline \multirow[t]{10}{*}{$\begin{array}{l}\text { Environmental } \\
\text { factor }\end{array}$} & 7. & $\begin{array}{l}\text { How did you come to know about the nutrition label? } \\
\text { Probe: Did you learn about it from your parents, teachers, friends, } \\
\text { or media? }\end{array}$ \\
\hline & 8. & $\begin{array}{l}\text { Have you ever seen your parents, other family members, or } \\
\text { friends read the nutrition label when purchasing packaged food or } \\
\text { beverages? }\end{array}$ \\
\hline & & $\begin{array}{l}\text { Probe: Did the nutrition label influence them to buy packaged food } \\
\text { or beverages? }\end{array}$ \\
\hline & & $\begin{array}{l}\text { Do you read the nutrition label when you buy packaged food or } \\
\text { beverages after seeing their advertisements in media? } \\
\text { Probe: Do you trust what is conveyed in the advertisements? }\end{array}$ \\
\hline & 10. & $\begin{array}{l}\text { These are two different nutrition information panels (NIP). Please } \\
\text { choose one of the NIPs and describe what you like or dislike about } \\
\text { its format and design. }\end{array}$ \\
\hline & 11. & $\begin{array}{l}\text { In your opinion, how can the NIP be improved to be more attractive? } \\
\text { Probe: How about the colour/design/position of the NIP? }\end{array}$ \\
\hline & 12. & $\begin{array}{l}\text { How do you prefer to learn about the nutrition label, conventionally } \\
\text { or using new media or technology? }\end{array}$ \\
\hline & & $\begin{array}{l}\text { Probe: What else do you want to know about the nutrition label? } \\
\text { Why do you want to know these things? }\end{array}$ \\
\hline & 13. & $\begin{array}{l}\text { In your opinion, what is the best way to educate adolescents to use } \\
\text { the nutrition label when choosing their food? }\end{array}$ \\
\hline & & $\begin{array}{l}\text { Probe: Why do you think an adolescent does not use/read the } \\
\text { nutrition label when purchasing packaged food and beverages? }\end{array}$ \\
\hline
\end{tabular}

and the credibility of information on nutrition labels.

\section{Knowledge of nutrition labels}

In general, the participants described nutrition labels as information on the nutrient content of the food and its health implications. The majority of participants described nutrition labels as lists of nutrients and the amounts that were present in the food item. For example, one participant commented: 
Table 2. The characteristics of participants

\begin{tabular}{lcc}
\hline Characteristics of participants $(n=33)$ & $n$ & $\%$ \\
\hline Gender & & \\
Male & 11 & 33.3 \\
Female & 22 & 66.7 \\
Age (years) & & \\
13 & 12 & 36.4 \\
14 & 18 & 54.5 \\
16 & 3 & 9.1 \\
Ethnicity & & \\
Malay & 24 & 72.7 \\
Chinese & 7 & 21.2 \\
Indian & 2 & 6.1 \\
BMI-for-age (z-score) ${ }^{\dagger}$ & & \\
Underweight (z-score <-2SD) & 2 & 6.1 \\
Normal ( $\mathrm{z}$-score $\geq-2$ SD \& $\leq 1$ SD) & 31 & 93.9 \\
The frequency of pre-packaged food purchase in the past week & & \\
Never & 8 & 24.2 \\
$1-2$ times/week & 18 & 54.5 \\
$3-4$ times/ week & 7 & 21.2 \\
More than 4 times / week & 0 & 0.0 \\
Do you know about nutrition labels? & & \\
Yes & 30 & 90.9 \\
No & 3 & 9.1 \\
The frequency of nutrition labels reading during food purchasing & & \\
Never & 15 & 45.5 \\
Sometimes & 10 & 30.3 \\
Always & 8 & 24.2 \\
\hline
\end{tabular}

${ }^{\dagger}$ Classification based on WHO Growth Reference 5-19 years, BMI-for-age (5-19 years) (WHO, 2007)

"It tells how much sugar is in the food. It also shows energy and protein contents in that food" (FGD406, 13-year-old boy).

Another participant also responded:

"It shows how much fat is contained in the food. We can also know the sugar content of the food from the panel, that is, whether it is high or appropriate for our consumption" (FGD407, 14-year-old girl).

Further, participants described nutrition labels as tools to choose healthy foods. Most were concerned about the health benefits of the food that they purchased. Some of the responses were:

"Nutrition label tells if the food is good for our health. If we over consume a particular nutrient, we can get sick. If we eat more fat, we can become obese or get other diseases" (FGD305, 16-year-old girl).

"I want to be healthy. The label tells me how much sugar they put in a food. If we take much sugar, we can get diabetes. To stay healthy, I will read the sugar content on the label to choose more nutritious food" (FGD505, 14-year-old girl).

\section{Misperception of nutrition labels}

Some participants reported that the information on nutrition labels was confusing. Despite being well-informed about nutrition labels, they were not 
able to differentiate nutrition labels with other information on food labels such as the expiry date and list of ingredients. For example:

"Nutrition label is the expiry date on food packaged. I always read the expiry date to know the lifespan of a food product. It tells me if the food is already rotten. Sometimes I read the quantity of the food on the package" (FGD101, 13-year-old boy).

"Nutrition label tells us whether the food contains natural or artificial colouring. So we can assess the food from the health and safety aspects of ingredients before purchasing a food product" (FGD203, 16-year-old girl).

\section{Barriers to the use of nutrition labels}

Although most of the participants were familiar with nutrition labels, the majority of participants were not interested enough to read them. The findings revealed five barriers to the use of nutrition labels: the lack of interest, past experiences, hunger and food cravings, time constraints, and taste of food.

\section{Lack of interest}

Many participants felt that nutrition labels were not important. For example:

"Sometimes I do not feel like reading it. I am too lazy to read all of the information. It is not even important to me" (FGD202, 14-year-old boy).

"For me, it is not important. I do not know; I feel like I do not need to read the information when I buy prepackaged food" (FGD503, 14-yearold girl).

\section{Past experiences}

As some participants purchase the same foods regularly, they reasoned, there was no need for them to read the nutrition labels again.

"I do not read the nutrient contents because I have eaten that food before.
I do not think I have to read the information again. I already know the content" (FGD105, 14-year-old girl). "I always purchase that food. I already know the information because I have read the information before. So I do not have to read it again" (FGD407, 14-year-old girl).

\section{Hunger and food cravings}

The participants also stated that they preferred to purchase food that was ready to be consumed when they were hungry. They also purchased food they craved for even if they were not hungry. Therefore, reading nutrition labels was not important. Some participants expressed:

"I buy food that I want to eat. Whenever I see food in the supermarket that I like to eat it, I will just buy it without even reading the information" (FGD403, 13-year-old girl).

"I do not care about reading the information because I am too hungry. I just want to purchase and eat the food" (FGD504, 14-year-old girl).

\section{Time constraints}

Some participants also mentioned they had no time to read nutrition labels except for price and expiry date. For example:

"Sometimes when we are rushing, we do not have enough time to read all of the information. We want to make it quick" (FGD303, 14-year-old boy).

"I have no time to read the panel because we need to buy many things when I go grocery shopping together with my parents. We will only purchase food that we want" (FGD506, 14-year-old girl).

Taste of food

Participants also indicated they chose food that looked delicious and appealing: "I bought food without reading the nutrition information because the 
food looks so tempting" (FGD205, 13-year-old girl).

"I already know that the food tastes so good. I want to eat it even though I know that the food contains a lot of sugar. I do not think I need to read the nutrition information" (FGD201, 13-year-old boy).

On the other hand, the potential health benefits of the food motivated some of the participants who read nutrition labels. These participants thought that nutrition labels would interest them if they were overweight or concerned about non-communicable diseases:

"I want to reduce my fat intake because I want to lose weight. So every time I purchase food, I will look for information on fat content" (FGD401, 13-year-old girl).

"Normally I will read the glucose content of food to monitor my daily sugar intake because I am afraid of having diabetes" (FGD304, 16-yearold girl).

In addition, participants reported that the information influenced their choice of food to purchase. They stated that they read nutrition labels when they wanted to avoid certain nutrients with health risks:

"It will influence me to buy food only if the nutrient content is good for my health. For example, I will purchase food that is low in fat..." (FGD102, 13-year-old boy).

"I will not buy food that is high in sugar. Nowadays there are diseases that afflict persons of any age. Therefore, I will not purchase food that is bad for my health" (FGD305, 16-year-old girl).

\section{Trusting nutrition labels}

Some participants reported that they were not convinced by the information found on nutrition labels. However, the majority of the responses were positive. For example:

"I believe that the information lon nutrition labels] is true because the food comes from a reputable manufacturer endorsed by the government" (FGD106, 14-year-old boy).

"I will trust the information if the food is good for the health. For example, I will trust the nutrition label on less fat or less sugar food" (FGD306, 16-year-old girl).

While most of the participants thought that the information in nutrition labels was truthful, several other participants did not seem to think so.

"I do not believe these kinds of information on certain products. It happened to me once before. I purchased a supposedly low-sugar yoghurt, but it ended up being too sweet. So I do not trust the information so much" (FGD304, 16-year-old girl). "I do not trust the information because the manufacturer can manipulate the details. They always claim that food is nutritious to attract buyers. However, it is actually high in fat and sugar, which is unhealthy" (FGD402, 13-year-old girl).

\section{DISCUSSION}

This study was conducted to explore the personal factors that influence the practice of reading nutrition labels amongst adolescents. The participants reported low usage of nutrition labels when purchasing food, even though a majority reported they recognised nutrition labels. Four sub-themes were identified reflecting personal level factors: knowledge, misperception, awareness and trust of nutrition labels information.

The increasing prevalence of overweight and obese individuals in Malaysia (Poh et al., 2013) has directed the attention of policymakers to the 
provision of nutrition information as an important tool to promote healthier eating habits. The regulations for mandatory nutrition labelling and nutrition claims in Malaysia have been implemented since 2003. Besides, the Ministry of Health Malaysia has been engaged in various activities to enhance the knowledge of consumers and awareness of nutrition labelling. For example, one of the aims of the "Healthy Eating Through Healthy Shopping" programme was educating the participants to read nutrition labels when making smart food choices in general (NCCFN, 2016). Nevertheless, there is no education programme focused on nutrition labelling among adolescents conducted by either the government or private bodies.

The use of nutrition labels enables consumers to make healthier food choices by comparing the nutritional values of similar food products to decide which one has the higher or lower amount of nutrients. However, studies have shown that most consumers do not refer to nutrition labels when purchasing food. Campos, Doxey \& Hammond (2011) observed that the use of nutrition labels is lower among children, adolescents and older adults who are obese. The study highlights challenges regarding consumer understanding and appropriate use of labelling information. Studies have also found that adolescents had low usage of nutrition labels and most of them could not interpret information provided in nutrition information panel (Talagala \& Arambepola, 2016; Saha et al., 2013).

In the present study, most of the participants were familiar with nutrition labels, even though the majority reported they would not read them when purchasing foods. These findings are similar to a previous study which demonstrated low nutrition labels usage among adolescents (Wojcicki \& Heyman, 2012). Nonetheless, the participants could understand nutrition labels and describe them as providing information on nutrient contents and their importance to health. Similar results have been reported by an earlier study on adults (Wahlich, Gardner \& McGowan, 2013).

Additionally, some of the participants were confused between nutrition labels and other information on food labels such as expiry date and ingredients. Previous studies have shown that adolescents pay more attention to the expiry date, manufacturing date and also the list of ingredients (Talagala \& Arambepola, 2016; Jacobs, deBeer \& Larney, 2011) than they do to the nutrition panel.

Some participants reported that their main reason for using nutrition labels was because they were health conscious. Specifically, they were concerned about over-consuming some nutrients, such as fat and sugars, as these would make them fat or cause diet-related diseases. These findings were consistent with those from a study of female college students in South Korea, where the participants were interested in reading information on the calorie, fat and sugar content because they wanted to control their weight and reduce their intake of energy or fat (Lim, Kim \& Kim, 2015). Similarly, another study found that individuals use nutrition labels and expressed their readiness to change their diet because of health-related concerns (Soederberg \& Cassady, 2015).

This study has also revealed five barriers to the use of nutrition labels among participants, namely, the lack of interest, past experiences, hunger and food cravings, time constraints, and taste of the food. Results from the present study are consistent with other studies which have shown that the most common reasons given for not reading nutrition labels are the lack of interest (Ranilovic \& Baric, 2013) and time to read when making 
food purchases (Prieto-Castillo, RoyoBordonada \& Moya-Geromini, 2015). A study conducted in a supermarket found a low usage of nutrition labels by participants who considered the taste as the main reason for purchasing a particular food (Petrovici et al., 2012). A study based on interviews of female consumers in the United Kingdom found that reading nutrition information was viewed as time-consuming and tiresome. The respondents reported that they bought food that was convenient and quick to consume. Jacobs et al. (2011) also observed that the reasons for not reading nutrition labels were because of taste and price considerations (and more important than other reasons), lack of knowledge in nutrition and time constraints. According to Koen et al. (2018), another important reason was because they bought the same brand of a product all the time.

Most of participants in the present study were convinced that the information on the nutrition labels was truthful though some expressed scepticism about it. Our results are consistent with results of similar studies on younger respondents (Campos et al., 2011). Often, the participants were worried that food manufacturers could easily manipulate nutrition information to entice people to buy their products. A review by Tonkin et al. (2015) found similar concerns about their accuracy.

Psychological, economic and social factors played an essential role in influencing the use of nutrition labels. For example, adolescents from a lowincome family preferred to buy cheaper food even if they were thought to be unhealthy. Those from middle or highincomes preferred to buy more expensive but healthier foods. Social influences from parents and friends may also have an impact on the knowledge, attitudes and preferences of adolescents toward food (Bargiota et al., 2013), which may limit their use of nutrition labels.

To the best of our knowledge, this is the first qualitative study done in Malaysia to explore the personal factors that influence the understanding and practices of reading nutrition labels among adolescents. However, there are some limitations in the present study. First, the sample size was small and findings may not be generalised for all Malaysian adolescents. However, the focus group discussions were sufficient to obtain detailed information about the participants' personal views on this issue. Furthermore, the perspectives of the adolescents on their food choices may be influenced by their exposure to educational programmes at school, as well as gender, race, socioeconomic status, and other factors that have not been addressed in this study. Future research should explore the opinions of adolescents based on gender, race or socioeconomic status.

\section{CONCLUSION}

Personal factors such as knowledge, misperception, awareness and trust on nutrition labels information have significant impact on the practice of reading nutrition labels among adolescents. Food manufacturers may need to communicate better and design more effective nutrition labels. The findings of this study can provide important information to improve knowledge, attitude and practices of reading nutrition labels among adolescents.

\section{Acknowledgements}

The authors would like to thank the Negeri Sembilan State Department of Education and all the teachers and students who were involved and provided assistance to the study.

\section{Authors' contributions}

NJ, led the data collection, conducted the study, data analysis and interpretation, prepared the draft of the manuscript and reviewed the 
manuscript; NMN, advised on study methodology, data analysis and interpretation and reviewed the manuscript; RAT, principal investigator, conceptualized and designed the study, provided advice and interpretation of the data and reviewed the manuscript.

\section{Conflict of interest}

The authors declare no conflict of interest.

\section{References}

Baker P \& Friel S (2014). Processed foods and the nutrition transition: evidence from Asia. Obes Rev. 15(7):564-577.

Bandura A (1986). Social Foundations of Thought \& Action: A Social Cognitive Theory (1st ed). Prentice Hall, Michigan.

Bargiota A, Pelekanou M, Tsitouras A, \& Koukoulis GN (2013). Eating habits and factors affecting food choice of adolescents living in rural areas. Hormones 12 (2):246-53.

Campos S, Doxey J \& Hammond D (2011). Nutrition labels on pre-packaged foods: a systematic review. Public Health Nutrition 14(8):1496-1506.

IPH (2006). In: The Third National Health and Morbidity Survey 2006. Institute for Public Health, Ministry of Health Malaysia, Kuala Lumpur. From http://iku.moh.gov.my/index. php/research-eng/list-of-research-eng/ikueng/ nhms- eng/nhms-2006-eng [Retrived November 11 2016].

IPH (2014). In: National Health and Morbidity Survey 2014: Malaysian Adult Nutrition Survey. Institute for Public Health, Ministry of Health Malaysia, Kuala Lumpur. From: http:// iku.moh.gov.my/images/IKU/ Document/ REPORT / NHMS2014-MANS-VOLUME-1MethodologyandGeneralFind.pdf [Retrieved November 15 2016].

IPH (2015). In: National Health and Morbidity Survey 2015. Volume II: Non-Communicable Diseases, Risk Factors and Other Health Problems. Institute for Public Health, Ministry of Health Malaysia, Kuala Lumpur. From http:// iku.moh.gov.my/images / IKU / Document / REPORT/nhmsreport2015vol2.pdf. [Retrieved March 3 2017].

IPH (2017). In: National Health and Morbidity Survey 2017. Adolescents Nutrition Survey 2017. Institute for Public Health, Ministry of Health Malaysia, Kuala Lumpur. From http://www.iku.gov.my/images/ IKU / Document / REPORT / NHMS2017/ NutritionSurveyNHMS2017.pdf. [Retrieved January 7 2018].
Jacobs SA, de Beer H \& Larney M (2011). Adult consumers' understanding and use of information on food labels: a study among consumers living in the Potchefstroom and Klerksdorp regions, South Africa. Public Health Nutr 14(3):510-522.

Jun LV, Yong C, Shengfeng W, Qingmin L, Yanjun R, Sara K \& Liming L (2011). A Survey of nutrition labels and fats, sugars, and sodium ingredients in commercial packaged foods in Hangzhou, China. Public Health Rep 126(1):116-122.

Koen N, Wentzel-Viljoen E, Nel D \& Blaauw R (2018). Consumer knowledge and use of food and nutrition labelling in South Africa: a crosssectional descriptive study. Int $J$ Consum Stud doi:10.1111/ijcs. 12422

Landis JR \& Koch GG (1977). The measurement of observer agreement for categorical data. Biometrics 33:159-174.

Lim HJ, Kim MJ \& Kim KW (2015). Factors associated with nutrition label use among female college students applying the theory of planned behaviour. Nutr Res Pract 9(1):63-70. doi:10.4162/nrp.2015.9.1.63

$\mathrm{MOH}$ Malaysia (2010). In: Guide to Nutrition Labelling and Claims 2010. From https:// extranet.who.int/nutrition/gina/sites / default/files/MYS\%202010\%20 Guide\%20 to $\% 20$ Nutrition $\% 2$ Labelling\%20 and $\% 20$ Claims.pdf [Retrieved January 1 2016].

NCCFN (2016). National Plan of Action for Nutrition of Malaysia III, 2016-2025. National Coordinating Committee on Food and Nutrition, Ministry of Health Malaysia, Putrajaya.

Norazmir MN, Norazlanshah H, Naqieyah, N \& Khairil Anuar MI (2012). Understanding and use of food package nutrition label among educated young adults. Pakistan $J$ Nutr 11(10):836.

Ochola S \& Masibo PK (2014). Dietary intake of schoolchildren and adolescents in developing countries. Ann Nutr Metab 64(2):24-40.

Petrovici D, Fearne A, Nayga Jr RM \& Drolias D (2012). Nutritional knowledge, nutritional labels, and health claims on food: A study of supermarket shoppers in the south east of England. Br Food J 114(6):768-783.

Poh BK, Ng BK, Haslinda MD, Shanita SN, Wong JE, Budin SB, Ruzita AT, Ng LO, Khouw I \& Norimah AK (2013). Nutritional status and dietary intakes of children aged 6 months to 12 years: findings of the Nutrition Survey of Malaysian Children (SEANUTS Malaysia). $\mathrm{Br} J$ Nutr 110(S3):S21-35. 
Poh BK \& Nor Izzati A (2016). Physical activity and fitness: trends and programmes for children and adolescents in Malaysia. J Health Sport Sci Jutendo 7(2):66-70.

Prieto-Castillo L, Royo-Bordonada MA \& MoyaGeromini A (2015). Information search behaviour, understanding and use of nutrition labelling by residents of Madrid, Spain. Public Health 129(3):226-36. doi: 10.1016/j. puhe.2014.12.003.

Ranilović J \& Baric IC (2013). Perceived barriers and motives to reading nutrition label among label 'non-users' in Croatia. Croatian Journal of Food Technology, Biotechnology and Nutrition 8(1-2):52-57.

Saha S, Vemula SR, Mendu VV \& Gavaravarapu SM (2013). Knowledge and practices of using food label information among adolescents attending schools in Kolkata, India. J Nutr Educ Behav 45(6):773-779.

Soederberg LM \& Cassady DL (2015). Relationships among food label use, motivation, and dietary quality. Nutrients 7(2):1068-1080. doi: 10.3390/nu7021068

Talagala IA \& Arambepola C (2016). Use of food labels by adolescents to make healthier choices on snacks: a cross-sectional study from Sri Lanka. BMC Public Health 16(1):739.
Talib RA, Lim SH, Fakhrurazi H, Buhari SS \& Poh BK (2013). Evaluation of existing printed nutrition education materials about childhood obesity. Malaysian Journal of Health Sciences $11(2): 55-62$.

Tonkin E, Wilson AM, Coveney J, Webb T \& Meyer SB (2015). Trust in and through labelling- a systematic review and critique. $\mathrm{Br}$ Food $J$ 117(1):318-338.

Wahlich C, Gardner B \& McGowan L (2013). How, when and why do young women use nutrition information on food labels? A qualitative analysis. Psychol Health 28(2):202-216. doi: 10.1080/08870446.2012.716439

Wojcicki JM \& Heyman MB (2012). Adolescent nutritional awareness and use of food labels: results from the National Nutrition Health and Examination Survey. BMC Pediatr 12:55.

WHO (2007). Growth References Data for 5-19 Years. World Health Organization, Geneva.

Yahya HM, Shahar S, Ismail SN, Aziz AF, Din NC $\&$ Hakim BN (2017). Mood, cognitive function and quality of life improvements in middle aged women following supplementation with polygonum minus extract. Sains Malaysiana 46(2):245-54. 